\title{
Local authority planning for the mentally disordered offender
}

\section{Recent government policy and legislation}

\author{
J. Elverstone, Angus Cameron and Pamela J. Taylor
}

\begin{abstract}
As part of a project dealgned to aseess the impact of the NHS and Community Care Act 1990 upon the care of patients discharged from special hospltals, an attempt was made to obtain local authortly community care plans. The dificulties encountered curing this exercise and the level of planning obtained for the mentally cisordered oftender as identilied in those plans, may be a couse for concem to clll those working in this field.
\end{abstract}

In the months prior to 1 April 1993 and the implementation of Part III of the National Health Service and Community Care Act 1990 ('The Act'), the importance of staff briefing and information dissemination, particularly among frontline staff dealing with the public, was highlighted. In the new 'consumer framework', informing service users how to gain access to services assumes an even greater importance than previously and is recognised as a key task for service providers. For the last two years the Department of Health and the Home Office had been undertaking a review of health and social services for mentally disordered offenders and others requiring similar services, publishing consultative documents and consulting throughout, and then publishing the final summary generally known as the Reed Report - at the end of 1992, with attendant local authority briefings and general publicity.

The Special Hospitals Service Authority (SHSA) was set up in 1989 to run the three special (high) security hospitals of England and Wales Ashworth, Broadmoor and Rampton. They had previously been administered directly from the Department of Health. The hospitals receive patients from all over England and Wales (as well as a few from Scotland, Northern Ireland and parts of the Commonwealth), providing that they have a mental disorder which can only be treated in high security. Patients who are admitted tend to spend a long time in the hospitals, on average about $\mathbf{8 . 5}$ years. There is thus a particularly high risk, borne out in reality, that such people could become disconnected from their local communities and forgotten. In theory therefore, the Act, with its emphasis on multi-agency consul- tation and collaboration, and associated policy guidance relating to care programming, was particularly welcome for this group of patients.

As a national service, the SHSA began a three year project, beginning in June 1993, to investigate the impact of the Act upon the care and planning for the special hospital patient. As part of an initial information-gathering exercise a comprehensive collection of local authority community care plans was attempted so that we could begin to build an overall picture of the services avallable for the mentally disordered offender. A second goal was to provide the basis for beginning to monitor the ways in which agencies that should be involved were planning for this client group.

In view of the importance placed on information dissemination, as outlined above, an attempt was made to obtain the local authority care plans by asking a secretary to make a quick telephone call to local authority social services departments. It quickly became apparent that staff at the local authorities receiving the calls were far from individually equipped to deal with this request. A research worker then took up the task.

\section{The study}

On a day in June, a research worker called 77 local authorities, using the telephone numbers in the Municipal Year Book 1991. People answering the call were asked if they could supply, or arrange to have supplied, a copy of the community care plan. The responses were recorded.

\section{Findings}

In only 43 calls (56\%) was a link made to the appropriate department with one transfer. However, that did not reflect the amount of information required from the researcher to effect the connection which ranged from giving the receptionist a description of what the plan was tonames of departments or personnel involved. 
In a further 19 cases two transfers were required; in nine calls, three or more calls were required; in three calls the researcher was privy to heated arguments between staff as to the appropriate department; in five calls the telephone was unanswered; and in one contact the researcher was asked to ring back on another day as there was no-one there who could deal with the call.

Community care plans were obtained from 73 of the authorities and an assessment was made as to the level of service planning for the mentally disordered offender client group. This was not intended to be an in-depth analysis of the care plans, simply a quick trawl of the sections pertaining to services for the mentally ill and services for those with learning disabilities. Of the 73 plans viewed, only $31(42 \%)$ plans identified mentally disordered offenders as a client group at all. Where they did identify them as a client group, the way in which they were identified and services outlined varied enormously from a simple mention of the completion of the Reed Report, through planning talks to discuss the recommendations of the Reed Report, through to actually identifying approximate numbers of users and services currently avallable and direction of future planning.

\section{Comment}

Such a brief exercise cannot possibly lead to any judgement of good or bad planning and, as outlined above, this was not our intention in approaching local authorities for their care plans. However, the results of this exercise would appear to indicate that local authorities cannot be complacent either about their service planning, or with regard to training for their staff involved with the public.

The fact that, of all the care plans reviewed, more than one half did not even identify mentally disordered offenders as a client group must be a cause for concern. This concern is heightened by the effects of the changes in funding for places in hostels, registered homes and related projects for the whole range of people requiring such facilities. Funds were transferred from the Department of Social Security to the local authorities on 1 April 1993. In spite of the risks for the community as well as the individuals concerned if adequate provision is not made, people who fall into the broad category of mentally disordered offender tend to fare badly when in competition with other groups traditionally seen as more 'deserving'. In the short term, competition for scarce resources is inevitable but if one client group is not even entered into the competition, satisfactory planning and longer term development of adequate resources becomes impossible.

A further legitimate question arises in view of the extent of the difficulties encountered in obtaining information on care planning. If the frontline staff of local authorities are not sufficiently informed as to their own 'products', nor, in a few cases, sufficiently socially skilled to communicate competently even with a professional researcher who could patiently explain and re-explain her needs, are they sufficiently equipped to deal effectively with members of the various client groups who may contact them with equally legitimate questions? Sensitive, informed responses to ultimate service users, if they do make contact, might literally be a life or death issue, but health and other professional care workers should also be able to expect a uniformly helpful response even if all the relevant information is not yet in place. The goal of interagency working is that much harder to effect without this.

\section{Recommendations}

Raise awareness of mentally disordered offenders as a client group. Perhaps each forensic psychiatrist and each general psychiatrist with an interest in the field should personally approach the local authorities within their catchment area for copies of their care plans and for discussion.

More urgency in planning for this client group.

A designated contact person with lead responsibility for this area of service planning in each local authority office, clearly communicated to all members of hospital psychiatric teams.

A date fixed by each authority for completion of detailed planning for this client group with this being monitored by an outside agency such as the Social Services Inspectorate.

Ongoing training and appropriate information for all reception staff.

J. Elverstone, Research Worker; *Angus Cameron, Probation Development Advisor SHSA/ ILPS; and *Pamela J. Taylor, Head of Medical Services; Special Hospital Services Authority. Charles House, 375 Kensington High Street, London W14 8QH

*Also Department of Forensic Psychiatry. Institute of Psychiatry, London SE5 8AF 